\title{
The Impact of Community Outreaches on Tuberculosis Case Notification in Sardauna Local Government Area, Taraba State, Nigeria
}

\author{
Markus Nzunde1, Haruna Ismaila Adamu1 ${ }^{*}$, Jalal-Eddeen Abubakar Saleh1, \\ Chukwuebuka Ugwu1, Abe Agbu² \\ ${ }^{1}$ Communicable and Non-Communicable Diseases, World Health Organization, Abuja, Nigeria \\ ${ }^{2}$ Ministry of Health, Jalingo, Taraba State, Nigeria \\ Email: *adamuh@who.int
}

How to cite this paper: Nzunde, M., Adamu, H.I., Saleh, J.-E.A., Ugwu, C. and Agbu, A. (2020) The Impact of Community Outreaches on Tuberculosis Case Notification in Sardauna Local Government Area, Taraba State, Nigeria. Open Access Library Journal, 7: e6856.

https://doi.org/10.4236/oalib.1106856

Received: September 24, 2020

Accepted: October 27, 2020

Published: October 30, 2020

Copyright $\odot 2020$ by author(s) and Open Access Library Inc.

This work is licensed under the Creative Commons Attribution International License (CC BY 4.0).

http://creativecommons.org/licenses/by/4.0/

\begin{abstract}
Background: According to the Global TB report 2019, a total of 7 million new TB cases were notified globally in 2018, out of an estimated 10 million cases, resulting in a gap of 3 million between the incident and notified TB cases, with Nigeria contributing $12 \%$ of such a gap. To address this gap, the WHO Nigeria country office, in collaboration with NTP and support from USAID engaged TB surveillance officers in 12 priority States in 2018. Since then, several active TB case finding interventions have been implemented in collaboration with the TB control programs of the affected states. This study examined the impact of one of such interventions in Taraba State, Northeastern Nigeria. Method: Retrospective review of the impact of targeted community TB outreaches in Sardauna Local Government Area (LGA) of Taraba State, Northeastern Nigeria, from $1^{\text {st }}$ June to $31^{\text {st }}$ December 2019. Results: Independent samples of t-test and Levene's test for equality of variance showed a statistically significant increase $(p<0.05)$ in the number of confirmed TB cases notified by the health facilities in Sardauna LGA. Thus, this intervention was impactful in increasing the number of notified confirmed TB cases and therefore should be expanded to other hard to reach (HTR) communities in the state and the country at large. Conclusion: The intervention can increase the number of confirmed TB notifications in deprived and hard to reach communities thereby reducing the huge gap between the incident and notified TB cases in the LGA, state and country.
\end{abstract}

\section{Subject Areas}

Infectious Diseases 


\section{Keywords}

Tuberculosis, Surveillance, WHO, USAID, Taraba, State, LGA, Hard to Reach Area, National TB Control Programme, Community TB Outreach, Northeastern Nigeria

\section{Introduction}

According to the Global TB report 2019, a total of 1.2 million people died from TB in 2018, making it the leading cause of death due to a single infectious agent [1]. Furthermore, a total of 7 million new TB cases were notified globally in 2018, out of an estimated 10 million cases resulting in a gap of 3 million between the incident and notified TB cases. Nigeria notified only $25 \%$ of its estimated TB cases in 2018 , resulting in a huge gap of $75 \%$ between the incident and notified TB cases. This translates to $12 \%$ of the global gap between incident and notified TB cases [1]. This gap includes all forms of TB, including children, who are often neglected in TB control efforts [2].

In 2018, the World Health Organization (WHO), with support from the United States Agency for International Development (USAID) engaged surveillance officers in 12 priority States, Taraba State inclusive, with the sole aim of supporting the National TB Programme (NTP) in improving this low TB notification, thereby reducing the huge gap between the incident and notified TB cases. Following robust discussions and brainstorming among stakeholders, innovative ways to find missing TB cases and improve TB cases notification were approved. One of these innovations is targeted community TB outreaches in hard to reach areas of Sardauna LGA, Taraba State, Northeastern Nigeria. This activity was carried out from June to December 2019 in Sardauna LGA which is one of the 16 LGAS in Taraba State. It is one of the hard to reach (HTR) LGAs in the State with high TB burden and many communities not accessible for health services especially during the peak of the raining season July to September annually.

Taraba State is one of the 36 States of the Federal Republic of Nigeria with an estimated population of 3.3 million people occupying an average of 52,000 sq.km in the northeastern region of the country. Sardauna is one of the 16 LGAs of the state located in the central senatorial district and is one of the HTR LGAs. Sardauna LGA has an estimated population of 327,000 people living on the highest plateau in Nigeria. Majority of the people are subsistence farmers and few trans-border traders between Nigeria and Cameroun.

Kurmi, the control LGA is also HTR in nature, located in the same senatorial district as Sardauna, with similar demographic characteristics except that it in low land and thick rainforest climate (see Figure 1).

Problem Statement: Globally, there is a huge gap between notified and estimated TB incident cases. Nigeria contributed $12 \%$ of this gap (missed TB cases) in 2018 as it reported only one out of four estimated incident TB cases [1]. The 

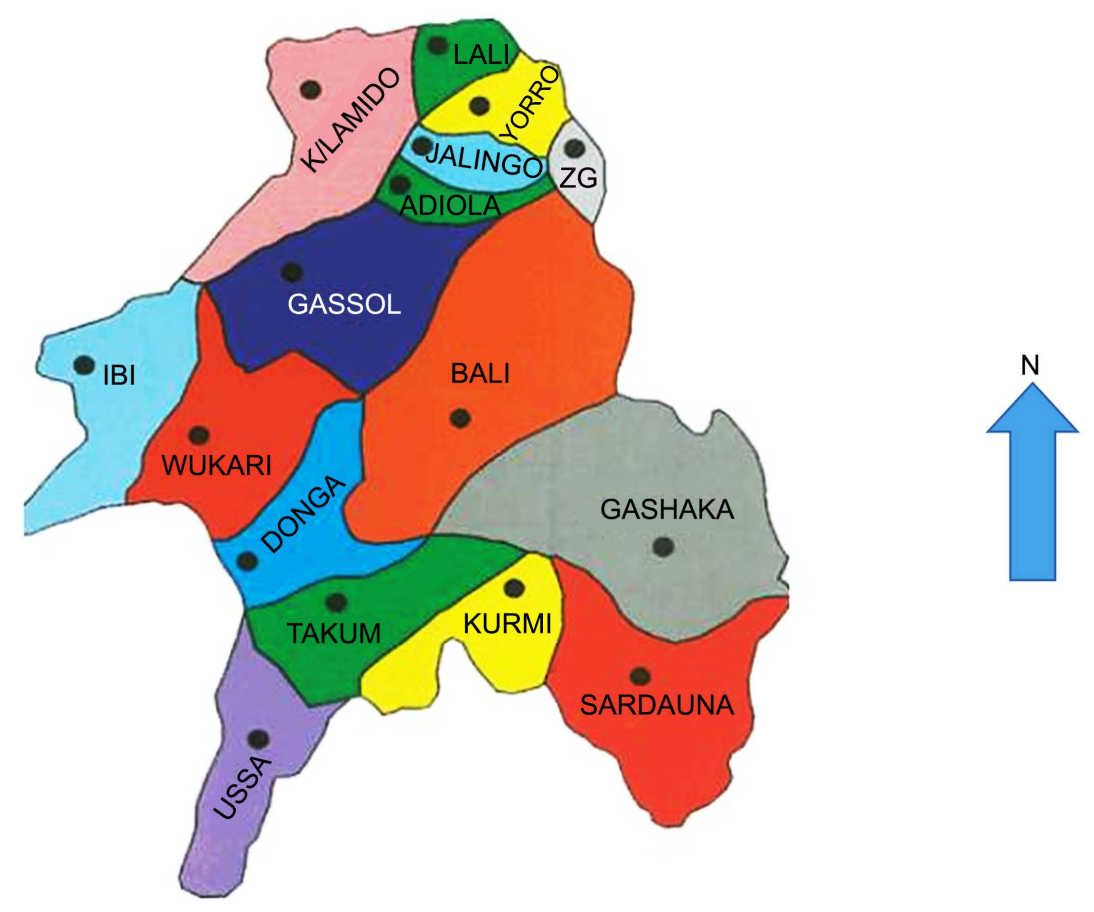

Figure 1. Map of Taraba showing Sardauna and Kurmi LGAs.

WHO, in collaboration with National TB Control Programme (NTP) and support from USAID, implemented innovative active TB case finding approaches to bridge this gap. One of these is the targeted community TB outreach in hard to reach areas of Mambilla Plateau, Sardauna LGA, Taraba State, Northeastern Nigeria. The purpose of this study was to look at the impact of this intervention on TB notification in the affected communities. The results and lessons learnt will also be used for possible expansion of the intervention to other similar communities in the state and the country at large.

Justification for the Study. The 2012 Nigeria National TB prevalence survey revealed among others that most of the missed $\mathrm{TB}$ cases are in the communities, hence the need to plan and implement active community based innovative approaches to find and treat these cases, thereby reducing the gap between the expected incident and notified TB cases.

\section{Method}

The WHO document titled "Baseline assessment of community-based TB services in 8 WHO ENGAGE-TB priority countries" was a very useful guide throughout the intervention period [3]. The intervention took place between $1^{\text {st }}$ June and $31^{\text {st }}$ December 2019 in the HTR communities of Sardauna LGA, Taraba State. After the intervention had ended, TB notification data were obtained retrospectively and was compared with similar data obtained over the same period in 2018 when the intervention did not take place. Data from a control HTR LGA (Kurmi) within the same senatorial district was collected for comparison. The variables collected were the number of presumptive and confirmed TB cases no- 
tified from the affected health facilities during both pre-intervention and post intervention periods.

An interventional retrospective study uses Kurmi as control LGA and Sardauna as intervention (targeted community TB outreaches) LGA. Both LGAs are in the same senatorial district and share similar demographic characteristics.

Raw figures and proportions were reported with appropriate graphs and charts. Furthermore, independent samples t-test was conducted to compare the means of presumptive and confirmed TB cases notified from all the health facilities within Sardauna (intervention) and Kurmi (control) LGAs over the periods before and after the interventions. T-test values with levels of significance set at $5 \%$ were reported. Statistical analyses were conducted with Microsoft Excel version 2013 and IBM SPSS version 20.

\section{Results}

Thirteen (13) targeted community outreaches were conducted in Sardauna LGA between June and December 2019, leading to the screening of 7094 people or TB, 871 presumptive TB which were all subsequently tested with GeneXpert $\mathrm{MTB} / \mathrm{RIF}$ assay, resulting in 98 confirmed TB cases (see Figure 2). When these figures were added to the routine 1230 presumptives and 221 confirmed TB cases in the LGA for the same period, a total of 2101 presumptive TB and 319 confirmed TB cases were obtained (see Table 1). Thus the intervention had contributed $41.5 \%$ more presumptives and $30.7 \%$ more confirmed TB cases respectively in the LGA from June to December 2019. These contributions can be clearly seen in Figure 2 and Figure 3.

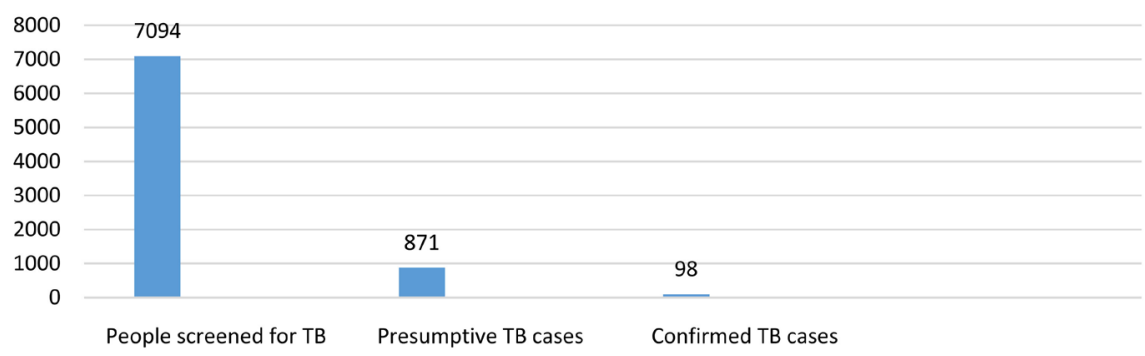

Figure 2. Bar chart of data reported during targeted TB outreaches in Sardauna LGA, Taraba State.

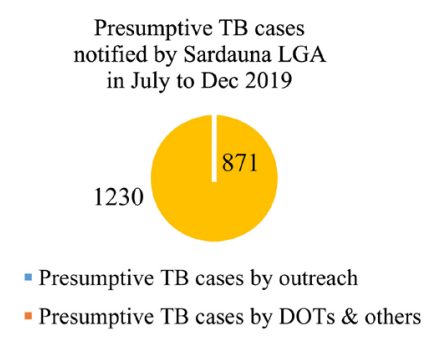

(a)

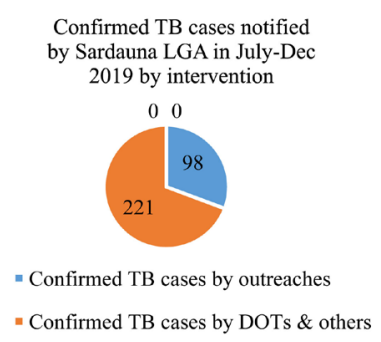

(b)

Figure 3. Pie charts of presumptive and confirmed TB cases contributed by outreaches to Sardauna LGA TB case notification, 2019. 
Table 1. Comparison of presumptive and confirmed TB cases before and after the intervention.

\begin{tabular}{ccccccccccccccc}
\hline & \multicolumn{4}{c}{ Pre-Intervention (Jul-Dec 2018) } & \multicolumn{4}{c}{ Post-Intervention (Jul-Dec 2019) } \\
\cline { 2 - 13 } & $\mathrm{N}$ & Presumptives & $\mathrm{t}$ & $p$ & Confirmed & $\mathrm{t}$ & $p$ & $\mathrm{~N}$ & Presumptives & $\mathrm{t}$ & $P$ & Confirmed & $\mathrm{t}$ & $p$ \\
\hline Control (Kurmi) & 7 & 132 & - & - & 30 & - & - & 7 & 472 & - & - & 54 & - & - \\
Intervention (Sardauna) & 10 & 1136 & $\star 2.34$ & 0.041 & 115 & 1.00 & 0.33 & 10 & 2101 & 2.24 & 0.041 & 319 & $\star 2.39$ & 0.037 \\
\hline
\end{tabular}

Note. Independent sample t-test. ${ }^{\star}$ Levene’s test.

Furthermore, similar increases in presumptives (85\%) and confirmed TB cases (177\%) can be seen when the LGA data for July to December 2019 is compared with that of the same period in 2018 as can be seen in Table 1. This means that if the intervention did not take place, a total of 965 presumptives and 204 confirmed TB cases would have been missed by the programme thereby fueling continuous TB transmission in the communities affected.

Likewise, similar increases can be noticed for the LGA if the presumptives (3897) and confirmed TB cases (523) for the entire 2019 were compared with those of 2018 (2034 and 282 respectively) representing an increase of $92 \%$ and $86 \%$ as can be seen in Figure 4 and Figure 5.

To further demonstrate the impact of the intervention, data for presumptives and confirmed TB cases over the same period were obtained from a contiguous LGA (Kurmi) where this intervention did not take place. Within the same period under review, Kurmi LGA had reported only 472 presumptives and 54 confirmed TB cases as compared with 2101 presumptives and 319 confirmed TB cases reported from Sardauna LGA for the same period, representing an increase of $345 \%$ presumptives and $491 \%$ confirmed TB cases respectively.

Table 1 displays results of the Independent samples t-test used to test for the statistical significance in the difference between the average presumptive and confirmed TB cases notified in the health facilities in control and intervention areas over the periods preceding and succeeding the intervention. As shown in the table, Levene's test for equality of variance was applied in the analysis. Clearly, the intervention yielded a statistically significant increase $(p<0.05)$ in the number of confirmed TB cases notified by the health facilities in Sardauna LGA. Although the number of presumptive TB cases reported by Sardauna LGA after the intervention was statistically significantly higher than that of Kurmi, a similar trend was observed before the intervention. Thus, this intervention is particularly impactful in increasing the number of notified confirmed TB cases. There was not a clearly attributable increase in presumptive TB cases accruing from the intervention across the LGAs.

\section{Discussion}

The study has clearly demonstrated that targeted community outreaches contributed significantly to both presumptive and confirmed TB case notification in Sardauna LGA, Taraba State. This finding agrees with the TB prevalence surveys carried out in Nigeria, Bangladesh, Indonesia and the Philippines [4] [5]. Their 


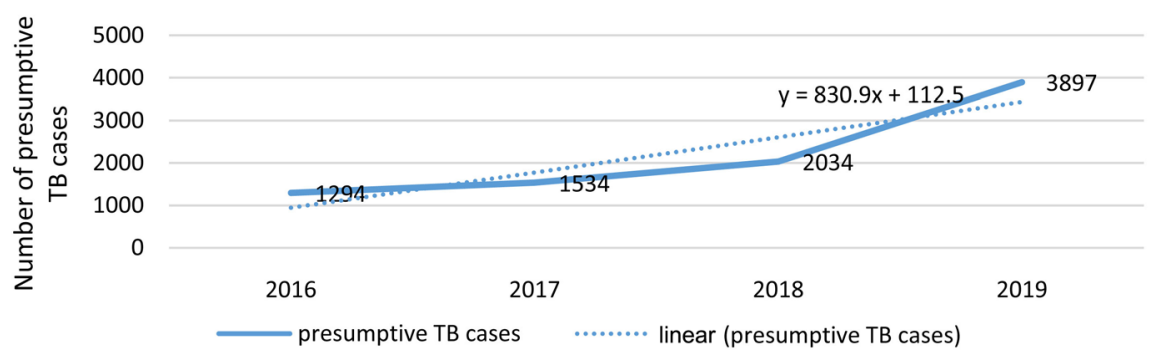

Figure 4. Trend of presumptive TB cases notified by Sardauna LGA 2016-2019.

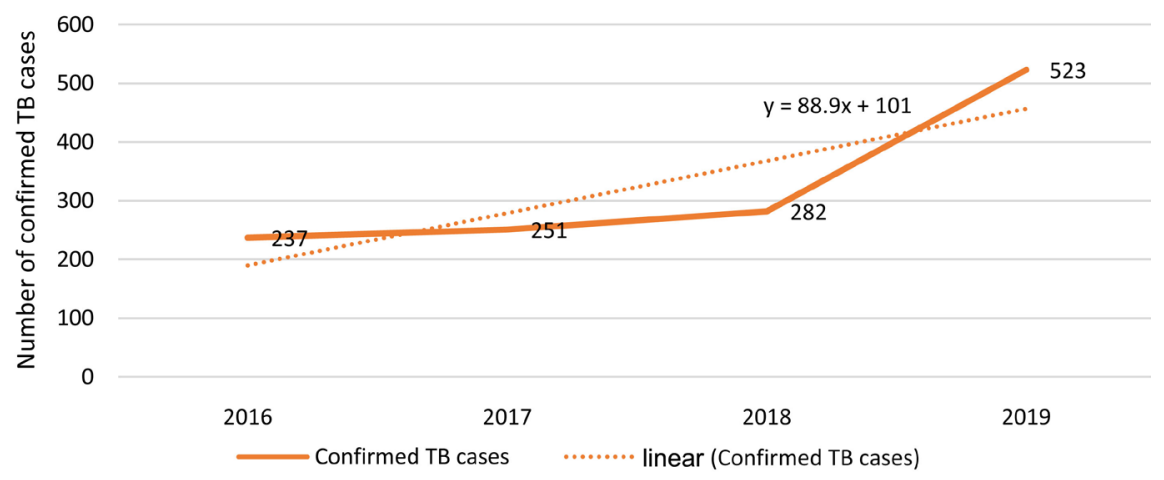

Figure 5. Trend of confirmed TB cases notified by Sardauna LGA, 2016-2019.

results showed that a large proportion of undetected TB cases remain in the communities and are aiding transmission to healthy persons. It is also in agreement with that of the study on models of community-based TB case finding in Nigeria as a way of addressing the low TB case detection crisis [6]. The patients detected by the intervention may have failed to present to the health facilities due to several reasons or barriers related to their low level of TB awareness [7], knowledge gap in TB etiology and management [8], poverty and inadequate TB service coverage [9], geographic accessibility [10], and stigma [11], only to be detected by the targeted community TB outreaches [12] [13]. Indeed, based on the KAP study conducted in 2008 , only $25 \%$ of Nigerians have correct knowledge of TB [14], and this may partly explain the lack of self-presentation of presumptive TB cases to health facilities for free diagnosis and treatment. The consequence of this is clearly the continuous transmission of TB (both drug sensitive and drug resistant) in the communities which is further fueled by factors related to globalization including poverty, rapid urbanization, and increased population mobility [15]. However, a similar intervention carried out in 32 targeted communities in Southern Ethiopia [16] was impactful only in improving the speed but not the extent of case finding for smear-positive TB cases. Conversely, in Northeast Nigeria, community outreaches were conducted in internally displaced persons' (IDP) communities, resulting in increased TB (and HIV) case notifications many times higher than national rates [13]. In Cambodia, similar active case finding (ACF) intervention targeting people aged 55 years and above in rural communities resulted in increased TB diagnosis, treatment initiation and treatment outcomes [17]. In Northern Uganda, an intervention 
that combined quality improvement with facility-led active case finding (QI-ACF) was implemented in 10 districts, resulting in an increase in overall TB case notification in the intervention districts [18]. Other countries where similar active TB case finding interventions led to increased notifications include Yunnan province of China [19], Kenya [20] and South Africa [21]. Thus, these studies have provided data that is critical for developing realistic strategies for the elimination of TB. These include, but not limited to, community outreaches, strengthening diagnosis of pulmonary $\mathrm{TB}$, and implementing targeted communication programs to reduce patient level delays, expanding public-private partnership to increase access to TB services, using rapid diagnostics, and providing social protection for vulnerable populations. These measures can accelerate countries' progress towards achieving End TB goals.

\section{Conclusion}

This study has clearly demonstrated the impact of community outreaches on TB case notification in hard to reach areas of Sardauna LGA, Taraba State, Northeastern Nigeria. The intervention is clearly capable of increasing both presumptive and confirmed TB cases in deprived and hard to reach communities thereby reducing the huge gap between the incident and notified TB cases in the LGA and the state in general. It is hoped that the intervention can be scaled up in all other HTR areas of the state for maximum impact.

\section{Conflicts of Interest}

The authors declare no conflicts of interest regarding the publication of this paper.

\section{References}

[1] WHO (2019) Global Tuberculosis Report 2019. World Health Organization, Geneva. https://www.who.int/teams/global-tuberculosis-programme/global-report-2019

[2] Adamu, H.I., Osoba, T.A., White, C.R. and Abdullahi, Y.G. (2018) Relationship between Caregiver's Quality of Life and Childhood Tuberculosis in Bauchi State, Northeastern Nigeria. Open Access Library Journal, 5, e4602. https://doi.org/10.4236/oalib.1104602

[3] WHO (2018) Baseline Assessment of Community-Based TB Services in 8 WHO ENGAGE-TB Priority Countries. WHO/CDS/GTB/THC/18.34.

https://www.who.int/tb/publications/2018/Baseline-assessment-community-TB-ser vices/en/

[4] NTBLCP (2012) National Tuberculosis and Leprosy Control Programme, TB Prevalence Survey Report. Federal Republic of Nigeria.

https://www.who.int/tb/publications/NigeriaReport_WEB_NEW.pdf

[5] Kak, N., Chakraborty, K., Sadaphal, S., AlMossawi, H.J., Calnan, M. and Vikarunnessa, B. (2020) Strategic Priorities for TB Control in Bangladesh, Indonesia, and the Philippines-Comparative Analysis of National TB Prevalence Surveys. BMC Public Health, 20, Article No.: 560. https://doi.org/10.1186/s12889-020-08675-9

[6] Adejumo, A.O., Azuogu, B., Okorie, O., Lawal, O.M., Onazi, O.J., Gidado, M., Mit- 
chell, E.M.H., et al. (2016) Community Referral for Presumptive TB in Nigeria: A Comparison of Four Models of Active Case Finding. BMC Public Health, 16, Article No.: 177. https://doi.org/10.1186/s12889-016-2769-7

[7] Dewi, C., Barclay, L., Passey, M. and Wilson, S. (2016) Improving Knowledge and Behaviours Related to the Cause, Transmission and Prevention of Tuberculosis and Early Case Detection: A Descriptive Study of Community Led Tuberculosis Program in Flores, Indonesia. BMC Public Health, 16, Article No.: 740. https://doi.org/10.1186/s12889-016-3448-4

[8] Agofure, O., Okandeji-Barry, O.R.A., Musa, E. and Odjimogho, S. (2018) Knowledge of the Prevention and Management of Tuberculosis among Residents of Bambuka Community Karim-Lamido Local Government Area of Taraba State. SM Journal of Public Health \& Epidemiology, 4, 1048.

https://smjournals.com/public-health-epidemiology/fulltext/smjphe-v4-1048.php

[9] Ereso, B.M., Yimer, S.A., Gradmann, C. and Sagbakken, M. (2020) Barriers for Tuberculosis Case Finding in Southwest Ethiopia: A Qualitative Study. PLoS ONE, 15, e0226307. https://doi.org/10.1371/journal.pone.0226307

[10] Asemahagn, M.A., Alene, G.D. and Yimer, S.A. (2020) Geographic Accessibility, Readiness, and Barriers of Health Facilities to Offer Tuberculosis Services in East Gojjam Zone, Ethiopia: A Convergent Parallel Design. Research and Reports in Tropical Medicine, 11, 3-16. https://www.dovepress.com/ https://doi.org/10.2147/RRTM.S233052

[11] Amenuvegbe, G.K., Francis, A. and Fred, B. (2016) Low Tuberculosis Case Detection: A Community and Health Facility-Based Study of Contributory Factors in the Nkwanta South District of Ghana. BMC Research Notes, 9, Article No.: 330. https://doi.org/10.1186/s13104-016-2136-X

[12] Sullivan, B.J. (2017) Barriers to Initiating Tuberculosis Treatment in Sub-Saharan Africa: A Systematic Review Focused on Children and Youth. Global Health Action, 10, Article ID: 1290317. https://doi.org/10.1080/16549716.2017.1290317

[13] Abdullahi, S.A., Smelyanskaya, M., John, S., Adamu, H.I., Ubochioma, E., Kennedy, I., Abubakar, F.A., Ago, H.A., Stevens, R. and Creswell, J. (2020) Providing TB and HIV Outreach Services to Internally Displaced Populations in Northeast Nigeria: Results of a Controlled Intervention Study. PLoS Medicine, 17, e1003218. https://doi.org/10.1371/journal.pmed.1003218

[14] Hassan, A.O., Olukolade, R., Ogbuji, Q.C., Afolabi, S., Okwuonye, L.C., Kusimo, O.C. and Ladipo, O.A. (2017) Knowledge about Tuberculosis: A Precursor to Effective TB Control-Findings from a Follow-Up National KAP Study on Tuberculosis among Nigerians. Tuberculosis Research and Treatment, 2017, Article ID: 6309092. https://doi.org/10.1155/2017/6309092

[15] Saleh, J.A. and Adamu, H.I. (2015) Globalization and the Spread of Multi-Drug Resistant Tuberculosis. Journal of Health, Medicine and Nursing, 18, 20-24. http://www.iiste.org/Journals/index.php/JHMN/article/view/25854

[16] Shargie, E.B., Mørkve, O. and Lindtjørn, B. (2006) Tuberculosis Case-Finding through a Village Outreach Programme in a Rural Setting in Southern Ethiopia: Community Randomized Trial. Bulletin of the World Health Organization, 84, 112-119. https://www.who.int/bulletin/volumes/84/2/112.pdf?ua=1

[17] Codlin, A.J., Monyrath, C., Ky, M., Gerstel, L., Creswell, J. and Eang, M.T. (2018) Results from a Roving, Active Case Finding Initiative to Improve Tuberculosis Detection among Older People in Rural Cambodia Using the Xpert MTB/RIF Assay and Chest X-Ray. Journal of Clinical Tuberculosis and Other Mycobacterial Diseas- 
es, 13, 22-27. https://doi.org/10.1016/j.jctube.2018.11.001

[18] Karamagi, E., Sensalire, S., Muhire, M., Kisamba, H., Byabagambi, J., Rahimzai, M., Mugabe, F., George, U., Calnan, J., Seyoum, D. and Birabwa, E. (2018) Improving TB Case Notification in Northern Uganda: Evidence of a Quality Improvement-Guided Active Case Finding Intervention. BMC Health Services Research, 18, Article No.: 954. https://doi.org/10.1186/s12913-018-3786-2

[19] Chen, J.O., Qiu, Y.B., Rueda, Z.V., Hou, J.L., Lu, K.Y., Chen, L.P., Su, W.W., Huang, L., Zhao, F., Li, T. and Xu, L. (2019) Role of Community-Based Active Case Finding in Screening Tuberculosis in Yunnan Province of China. Infectious Diseases of Poverty, 8, Article No.: 92. (Erratum in: Infectious Diseases of Poverty, 2020, 9, Article No.: 7.) https://doi.org/10.1186/s40249-019-0602-0 https://doi.org/10.1186/s40249-020-0625-6

[20] Okelloh, D., Achola, M., Opole, J., Ogwang, C., Agaya, J., Sifuna, P., Mchembere, W., Cowden, J., Heilig, M., Borgdorff, M.W., Yuen, C.M. and Cain, K.P. (2019) Lessons Learned from Community-Based Tuberculosis Case-Finding in Western Kenya. Public Health Action, 9, 53-57. https://doi.org/10.5588/pha.18.0085

[21] Mhimbira, F.A., Cuevas, L.E., Dacombe, R., Mkopi, A. and Sinclair, D. (2017) Interventions to Increase Tuberculosis Case Detection at Primary Healthcare or Community-Level Services. The Cochrane Database of Systematic Reviews, 11, CD011432. https://doi.org/10.1002/14651858.CD011432.pub2 